\title{
Mídias locativas: a internet móvel de lugares e coisas
}

\section{RESUMO}

Chamando atenção para a impressionante aceleração nas transformações dos meios tecnológicos de produção de linguagens, que, em menos de dois séculos, da invenção da fotografia já chega hoje até a internet móvel, este artigo se detém na cultura da mobilidade, uma variação avançada da cibercultura, baseada nos dispositivos móveis aliados ao sistema de posicionamento global (CPS). Uma das práticas mais relevantes que essa nova aliança vem trazendo é a das mídias locativas, fazendo emergir novas espacialidades de acesso, presença e interação que reconstituem os modos como nossos encontros com lugares específicos, suas bordas e nossas respostas a eles estão fundadas social e culturalmente.

\section{PALAVRAS-CHAVE}

mídias locativas

mobilidade

espaço

\begin{abstract}
Calling attention to the impressive acceleration of media transformations which, in less than two centuries, from the invention of photography reaches nowadays mobile internet, this article deals with the culture of mobility, an advanced variety of cyberculture based on mobile devices linked to GPS. One of the most relevant practices that this new alliance is bringing about is called locative media. They are provoking the emergency of new spacialities of access, presence, and interaction that reconstitute the way in which our encounters with specific places, their borders e our responses to them are socially and culturally founded.
\end{abstract}

\section{KEY WORDS}

locative media

mobility

space
Nos últimos anos, para compreender a hipercomplexidade cultural e comunicacional das sociedades contemporâneas, tenho utilizado como hipótese de trabalho a idéia de que essa hipercomplexidade advém da simultaneidade de seis formas de cultura que coexistem, sobrepõem-se, intercambiam-se e misturam-se inextricavelmente: a cultura oral, a escrita, a impressa, a cultura de massa, das mídias e cibercultura ${ }^{1}$. O critério empregado para essa divisão está baseado na gradativa introdução histórica de novos meios de produção, armazenamento, transmissão e recepção de signos no seio da vida social. Longe de se excluírem mutuamente, a tendência dos meios é cumulativa e integrativa. Os novos meios vão chegando, levando os anteriores a uma refuncionalização e provocando uma reacomodação geral na paisagem midiática.

Em um texto colaborativo do site New Media Literacies, encontrei uma divisão quase similar à minha, que apresenta as seguintes etapas na evolução histórica dos sistemas de mídia: ancestral (cultura oral), residual (cultura impressa), dominante (cultura de massas) e emergente (cultura participativa). O que é mais importante não é a divisão em si, mas a constatação de que a emergência de um novo sistema não apaga o que veio antes, mas adere como uma nova camada, tornando a ecologia midiática ainda mais estratificada.

Seguindo a minha divisão, vale lembrar que, embora as culturas oral, escrita e impressa ainda estejam vivas e ativas, não resta dúvida de que as três últimas - massiva, das mídias e cibercultura - são as mais nitidamente visíveis. Todo o quadro também nos leva a notar que, especialmente em países como o Brasil, apesar do domínio incontestável da cultura de massas, esta é apenas parte de uma ecologia midiática híbrida que se constitui em princípio organizador da sociedade. Os sistemas midiáticos consistem de tecnologias comunicacionais e das mais variadas práticas econômicas, políticas, institucionais e culturais que crescem com eles.

Já enfatizei em muitas ocasiões, mas não custa repetir, que cada uma das formações culturais apresenta caracteres que lhe são próprios e a distinção entre eles nos leva a constatar que as mídias não funcionam como um monolito indistinto. Embora misturada às outras, cada formação cultural funciona socialmente de maneiras diversas. A cultura dos meios de massa, do jornal à televisão, opera socialmente de modo muito diverso da cultura das mídias e de maneira ainda mais distinta do modo como opera a cibercultura. Quando isso é levado em consideração, evitam-se os equívocos correntes que nascem da imposição sobre uma formação cultural de critérios de julgamento e crítica que são empregados para uma formação cultural distinta.

Para os propósitos deste artigo, o que merece ser trazi-

\section{Lucia Santaella \\ PUC/SP \\ lbraga@pucsp.br}


do à baila é a impressionante aceleração das transformações dos meios tecnológicos de produção de linguagens, desde a revolução industrial que trouxe consigo a invenção da fotografia, do telégrafo e os germens da cultura de massas. No capítulo sobre Mediações tecnológicas e suas metáforas, do livro Linguagens líquidas na era da mobilidade (Santaella, 2007), explicitei que, do século XIX para cá, já alcançamos a quinta geração de tecnologias comunicacionais.

Os meios de comunicação de massa eletro-mecânicos (primeira geração: foto, telégrafo, jornal, cinema) e eletroeletrônicos (segunda geração: rádio, televisão) foram seguidos por aparelhos, dispositivos e processos de comunicação narrowcasting (terceira geração: TV a cabo, xérox, fax, vídeo cassete, walkman etc. que chamo de cultura das mídias). Ao mesmo tempo em que ia minando o domínio exclusivista dos meios de massa, a cultura das mídias preparava o terreno da sensibilidade e cognição humanas para o surgimento da cibercultura, dos computadores pessoais ligados a redes teleinformáticas (quarta geração). Estes, por sua vez, foram muito rapidamente sendo mesclados aos aparelhos de comunicação móveis (quinta geração), constituindo assim, em muito pouco tempo, cinco gerações de tecnologias comunicacionais coexistentes que, aliadas a saberes que delas se originam, práticas sociais e institucionais, políticas públicas, formas de organização burocráticas e fluxos do capital, "entretecem uma rede cerrada de relações, em que nenhuma delas é 'causa' das demais, mas todas se configuram como "adjacências históricas" fortemente articuladas, que expressam e simultaneamente produzem mutações nos modos de se perceber, conceber e habitar o tempo" (Ferraz, 2005, p. 52).

Pouco mais de dez anos se passaram desde a consolidação da cibercultura com a explosão da WWW e, hoje, em concomitância com o potencial aberto pela Web 2.0, a cultura da mobilidade, uma variação avançada da cibercultura, baseada nos dispositivos móveis, aliados ao sistema de posicionamento global (GPS) ${ }^{2}$, já começa a render frutos que têm chamado atenção de artistas e de teóricos e críticos da comunicação e cultura.

\section{A reavaliação dos discursos sobre perdas}

O que a emergente era da mobilidade vem colocando em relevo, antes de tudo, é a necessidade de reavaliação dos prognósticos tanto sobre o desaparecimento da experiência humana do lugar e das interações sociais em presença, quanto sobre a perda da integridade corporal do humano na intersecção com sistemas cibernéticos - computadores, organismos engenheirados biogeneticamente, sistemas espertos, robôs, andróides e ciborgues.

Para muitos, as tecnologias das redes de informação e interação criam um espaço virtual (um ciberespaço) independente, que transcende e se sobrepõe aos espaços do mundo cotidiano. Realidade virtual, telepresença e Second Life parecem, de fato, intensificar essa impressão de mundos paralelos autônomos. Para Dourish (Dou- rish, 2006, p. 6), entretanto, o mundo tecnológico não está separado do mundo físico, mas está incrustado nele, fornecendo novos modos de compreendê-lo e se apropriar dele. A mediação tecnológica do ciberespaço condiciona a emergência de novas práticas culturais. Não é por meio da criação de uma esfera separada que isso se dá, mas pela abertura de modalidades diferenciais de práticas que se inserem à sua maneira na vida cotidiana, refletindo e condicionando novas formas de acesso à informação e ao conhecimento. Os espaços eletrônicos estão firmemente situados na experiência vivida, motivados por ela e tomam forma em resposta às suas demandas.

\section{Cada vez mais, os recursos tecnológicos se hibridizam, transformando as mídias} locativas em um campo múltiplo,
disponível em muitas versões,
dependendo do modo como são
operadas e dos usos que lhes
são agregados.

Antes mesmo da emergência dos dispositivos móveis, que agora provocam a intersecção do ciberespaço com o espaço em que nossos corpos circulam, Harrison e Dourish (Harrison e Dourish, 1996) já se referiam ao ciberespaço como espaços híbridos. Argumentavam que, quando nosso avatar entra em um ambiente virtual colaborativo, ambos, o ambiente e o avatar, de fato, são virtuais. Entretanto, no ciberespaço, se as conexões entre as pessoas são virtuais, as projeções delas nos avatares não o são. O que é projetado na conexão é uma representação do próprio usuário. Cabe aqui uma analogia com a constatação de Freud de que, se no sonho os ladrões são fictícios, o medo é real. Assim também, no ciberespaço, se o avatar é uma mera representação virtual, a projeção é real. Ademais, sem a manipulação remota dessa representação por uma pessoa fisicamente situada, o espaço virtual não teria existência. Quando entramos em um ambiente virtual, usamos esse espaço midiático para criar um novo espaço híbrido que nos inclui como seres ditos físicos e reais.

As cidades também, atravessadas invisivelmente pelo fluxo de informações, foram reordenadas pelos sistemas tecnológicos das redes, gerando uma arqui tetura digital considerável. Muitos julgaram e continuam julgando que essas construções virtuais rizomáticas, compartilhadas por milhões de pessoas pelo mundo afora, cons- 
tituem-se em universos paralelos capazes de apagar significados e valores, estes sim verdadeiros, da vida real. Outros, entretanto, entre eles Castells (Castells, 2000), argumentam que a ciber-realidade é parte integrante da organização material, econômica, política das sociedades, sendo inclusive determinante nessa organização e significativa de sua real existência.

Tal intersecção, antes menos visível, do ciberespaço com a vida circundante, vem recebendo um novo impulso recentemente com os aparelhos móveis que permitem encontros com a tecnologia em situações sociais distintas, que criam a necessidade de entender os contextos e que nos dão a habilidade de transformar o espaço pela introdução da tecnologia. Tudo isso junto com a emergência de projetos variados de mídias locativas vem colocando em questão os maus presságios sobre perdas irrecuperáveis que feriam a integridade da nossa constituição humana e social.

De fato, as mídias locativas estão criando oportunidades para se repensar e re-imaginar o espaço cotidiano. Embora conectados à imaterialidade das redes virtuais de informação, não poderia haver nada mais físico do que GPS e sinais de Wi-Fi que trazem consigo outras maneiras de pensar o espaço e o que se pode fazer nele. Uma nova espacialidade de acesso, presença e interação se anuncia: espacialidades alternativas em que as extensões, as fronteiras, as capacidades do espaço se tornam legíveis, compreensíveis, práticas e navegáveis, possibilitando, sobretudo, práticas coletivas que reconstituem os modos como nossos encontros com lugares específicos, suas bordas e nossas respostas a eles estão fundadas social e culturalmente.

\section{0 território em expansão das mídias locativas}

A computação móvel e pervasiva (computadores em todos os lugares) é a chave para a compreensão das mídias locativas. No processo, o uso de sistemas de informação geográfica (GIS) espalhou-se das corporações e escritórios para as ruas e os campos, da administração pública e ambiental para um largo espectro de usos sociais. Desse modo, como lembra McCullough (McCullough, 2006), um dos mais profundos desafios das mídias locativas está em transmitir informação geográfica não mais nas tradicionais e pesadas janelas dos desktops, mas nas tecnologias finas e leves dos sistemas móveis e embarcados.

É bastante esclarecedora a explicação que nos é fornecida por André Lemos (no prelo) - pioneiro no Brasil no estudo das ciberurbes - sobre a constituição e abrangência das mídias locativas no seu atual estado da arte.

Um conjunto de processos e tecnologias [que] se caracteriza por emissão de informação digital a partir de lugares/objetos. Esta informação é processada por artefatos sem fio, como GPS, telefones celulares, palms e laptops em redes Wi-Fi ou Wi-Max, Bluetooth, ou etiquetas de identificação por meio de rádio freqüência $\left(R F I D^{3}\right)$. As mídias locativas são utilizadas para agregar conteúdo digital a uma localidade, servindo para funções de monitoramento, vigilância, mapeamento, geoprocessamento (GIS), localização, anotação ou jogos. Dessa forma, os lugares e objetos passam a dialogar com dispositivos informacionais, enviando, coletando e processando dados a partir de uma relação estreita entre informação digital, localização e artefatos digitais móveis.

Existem muitas classificações dos tipos de mídias locativas, mas, mais uma vez, é em Lemos (ibid) que se pode encontrar uma classificação relevante por estar baseada nas funções que elas desempenham, tais como: realidade móvel aumentada, mapeamento e monitoramento, geotags, anotação urbana e os games wireless que utilizam uma ou mais dessas funções.

As aplicações de realidade aumentada móvel referem-se a informações sobre uma determinada localidade visualizadas em um dispositivo móvel, aumentando a informação. Assim, um celular pode identificar uma pizzaria em local próximo e, por meio de links, ver a foto do lugar e ter acesso ao cardápio no website do restaurante.

\section{Tanto quanto espaço e lugar, outro conceito que as mídias locativas estão trazendo para 0 topo das considerações é o conceito de objeto que, na linguagem corrente, chamamos de coisas.}

As funções locativas também podem ser aplicadas a formas de mapeamento (mapping) e de monitoramento do movimento (tracing) no espaço urbano. Em sistemas que permitem o compartilhamento de $\operatorname{tags}^{4}$ (etiquetas), informações textuais digitais são agregadas a mapas, podendo ser acessadas pelos equipamentos móveis.

Celulares, palms, etiquetas RFID ou redes bluetooth são utilizados para indexar mensagens (SMS, vídeo, foto) a localidades. Essas práticas são chamadas de anotações urbanas.

Os games móveis ou sem fio utilizam celulares, palms e a rede internet para jogos executados entre jogadores no espaço das ruas e jogadores on line. Lenz (Lenz, 2007) apresenta 26 exemplos desse tipo de jogo e novos exemplos não cessam de aparecer.

Segundo o relatório da Escola Politécnica Federal de Lausanne, citado por Lenz (ibid.), "o contexto de uso 
mais comum dos sistemas móveis é a localização do usuário, visto que é fácil determiná-la e seria significativo usá-la para adaptar o comportamento de uma aplicação móvel". Uma vez que o fator mais relevante das mídias locativas é o contexto, Schmidt et al., também citados por Lenz, distinguem duas categorias de contexto: ambiente físico e fatores humanos. O primeiro referese às variáveis físicas como local (absoluto e relativo), condições (luz, temperatura etc.) e infraestrutura (recursos para a comunicação, computação, desempenho de tarefas etc.). Os fatores humanos relacionados ao contexto estruturam-se em: informação sobre o usuário (estado emocional, conhecimento de hábitos etc.), o ambiente social do usuário (co-localização em relação aos outros, interação social etc.) e as tarefas do usuário (atividade espontânea, atividade engajada, objetivos gerais etc.).

Cada vez mais, os recursos tecnológicos se hibridizam, transformando as mídias locativas em um campo múltiplo, disponível em muitas versões, dependendo do modo como são operadas e dos usos que lhes são agregados. Além dos sistemas de informação geográfica (GIS) e das tags de identificação de rádio freqüência (RFID), a linguagem de marcação de geografia (GML - geographic markup language ${ }^{5}$ ), e o sensoriamento ambiental distribuído podem ser utilizados nas estratégias das mídias locativas, também conhecidas como mídias táticas, na medida em que tratam o contexto como meio dinâmico de produção de atividades engajadas e não meramente como um arranjo preexistente de destinações. São táticas porque buscam a produção do sentido, mesmo quando uma posição estratégica é negada.

Recentemente tratei da estética politicamente orientada das mídias locativas (Santaella - no prelo). Outro aspecto que me parece bastante relevante é a vivificação dos lugares e das coisas que as mídias locativas estão propiciando, questão que passarei a discutir no que se segue.

\section{Espaço, lugar e coisas}

Não há um consenso entre os teóricos sobre o conceito de lugar, especialmente sobre a distinção conceitual entre lugar e espaço. No seu sentido convencional, espaço é uma noção matemática, uma representação formal que gera modelos provenientes de diferentes espécies de práticas científicas ${ }^{6}$. Segundo Dourish (Dourish, 2006), na interpretação predominante da relação entre espaço e lugar, o primeiro é visto como pré-dado e o segundo como um produto social. Distinta desta e bem mais complexa, no campo da análise social, é a interpretação de Certeau (Certeau, 1984), um dos autores mais influentes sobre o assunto. Para este, lugar é uma espécie de "localização".

É o espaço geométrico que dá conta do fato de que duas coisas não podem ocupar o mesmo lugar no espaço. Já o espaço é um produto social, um lugar praticado. Assim, uma rua, definida geometricamen- te pelo planejamento urbano, é transformada em espaço pelos transeuntes.

Noção bastante rica de lugar nos é fornecida por Harrison e Dourish (Harrison e Dourish, 1996). Para estes, espaço é a estrutura do mundo, é o ambiente tridimensional no qual objetos e eventos ocorrem e no qual eles têm posição e direção relativa. Lugar, por seu lado, é espaço investido de compreensão, de comportamento apropriado, de expectativas culturais. Uma vez que o mundo é espacial e tridimensional, noções de espaço perpassam nossa experiência cotidiana. Tudo se localiza no espaço, de modo que lugares também estão ligados ao espaço. Estamos localizados no espaço, mas agimos em lugares. O lugar é o modo como o espaço é usado. Portanto, é geralmente um espaço com algo que se lhe adiciona: sentido social, convenção, compreensão cultural sobre papéis, função e natureza etc. O sentido do lugar transforma o espaço. Lugares são criados e sustentados pelos padrões de uso. Em suma: a ação humana não é emoldurada apenas pelo espaço, mas por padrões de compreensão, associações e expectativas com que os lugares estão impregnados.

O privilégio da noção de lugar em detrimento de espaço, que se insinuava na concepção de Harrison e Dourish, em 1996, foi revista por Dourish no seu artigo de 2006. Afinal, do ponto de vista do designer, em meados dos anos 1990, tratava-se de criar lugares colaborativos para a prática e apropriação dos usuários nos ambientes do ciberespaço. Dez anos depois, o uso cada vez mais generalizado de redes tecnológicas por meio de sistemas sem fio e telefonia celular vem alterando os modos como compreendemos as relações entre as pessoas, ações e os espaços em que elas ocorrem. Uma vez que questões de mobilidade estão indissoluvelmente ligadas a questões de espacialidade, no seu artigo de 2006, mais próximo de Certeau, Dourish concede ao espaço, tanto quanto ao lugar, o estatuto de produto de práticas sociais.

De fato, a tecnologia móvel nos força a reconsiderar o espaço, a legibilidade do espaço, o modo como as pessoas reencontram o espaço cotidiano, pois, quando o movimento da cidade e a mobilidade humana - ambos tecnologicamente mediados - se cruzam, múltiplas espacialidades podem se interseccionar ${ }^{7}$. Assim, o papel da computação ubíqua e pervasiva no ambiente urbano tornou-se hoje questão primordial para os estudiosos da cibercultura nos umbrais desta era da hipermobilidade.

Tanto quanto espaço e lugar, outro conceito que as mídias locativas estão trazendo para o topo das considerações é o conceito de objeto que, na linguagem corrente, chamamos de coisas. Longe de serem inocentes, as coisas trazem consigo uma robusta tradição filosófica. Não podemos nos esquecer de que, em sociedades capitalistas, as coisas deixaram de ser coisas. São mercadorias e, como tal, impregnadas de fetichismo, valores psíquicos dissimulados que o capital adere às coisas. Trata-se aí de uma lógica tão onipresente de que nem 
mesmo nossos afetos e paixões se safam, pois estes são também perfeitamente intercambiáveis de acordo com a lei universal da equivalência. Freud considerou o fetiche como um substituto simbólico do objeto irrecuperável, perdido no trauma original. Para Marx, o fetichismo é o resultado da alienação do produto em relação à sua produção e origem. Comum na concepção de ambos é o fato de que a vida dos objetos é meramente ilusória, pois o objeto fetiche é mera costura de um vazio, para Freud, e um fascínio ocultador, para Marx.

Diante disso, é no mínimo ingênuo reivindicar a possibilidade de interceder teórica ou praticamente pelo retorno dos objetos à vida. Entretanto, os projetos de mídias locativas estão acenando com novos potenciais que parecem merecer considerações cuidadosas, sem a pressa dos julgamentos já prontos.

\section{Tornar visível 0 invisível, animar 0 inanimado}

Em agosto de 2004, no evento SIGGRAPH, Bruce Sterling, escritor de ficção científica, do gênero ciberpunk, sob o título de "Quando os blobjetos governarem a Terra", proferiu um discurso sarcástico e genial, em que profetizava um mundo em que os objetos passariam de blobjetos a spimes (ambas as palavras de invenção própria). Um ano depois, publicou o livro Shaping Things, no qual fornece explicações bem claras do sentido que dá às suas estranhas palavras. A tese do livro está fundamentada na teoria do design, tecnologia e história e analisa como os dispositivos que os designers produzem transformam a sociedade, a nós mesmos e ao próprio design. A trajetória histórica, por ele traçada, vai das ferramentas a partir dos artefatos (ferramentas dos agricultores) para as máquinas (dispositivos para clientes), e dos produtos (compras efetuadas pelos clientes) até os gizmos (plataformas dos terminais de usuários). Os blobjetos são os objetos computacionais criados pelos designers. O futuro será definido pelos spimes.

Spimes são objetos sensíveis ao lugar, sensíveis ao ambiente, auto-conectados, auto-documentados, indentificáveis na sua unicidade e expelem dados sobre si mesmos e seu ambiente em grandes quantidades. Um universo de spimes é um universo informacional com milhões desses experimentos em potência. Hackers, ativistas, advogados, competidores, designers, todos nós poderemos pesquisar a corrente de dados para descobrir, por exemplo, o que vai acontecer com a sola de nossos tênis no fim de sua vida. Vão ser reciclados e transformados no piso do pátio de uma escola ou vão se transformar em aerosol cancerígeno? Em suma: tomaremos conhecimento da vida dos objetos desde os seus berços até seus túmulos, o que nos tornará mais conscientes do papel ecológico dos objetos no mundo. Para Doctorow (Doctorow, 2005), os spimes são os dispositivos últimos dos "hacktivistas" - um ponto limite para tornar os frutos negativos da produção industrial visíveis e óbvios.

No mesmo ano em que Sterling publicava seu livro, o relatório da internet da União de Telecomunicação Internacional ${ }^{8}$, com o título de "Internet das coisas" e com toda a seriedade, detectava um futuro para a internet muito similar às irônicas profecias de Sterling. O documento cita as palavras de Mark Weiser, falecido excientista chefe do Centro de Pesquisa da Xérox em Palo Alto: "as tecnologias mais profundas são aquelas que desaparecem. Elas se entretecem no tecido da vida cotidiana até se tornarem indistinguíveis dele". Weiser estava se referindo aí à disponibilização crescente e à visibilidade decrescente do poder de processamento. Por meio de dispositivos dedicados, os computadores vão gradativamente sumir da nossa vista, enquanto as habilidades de processamento de informação vão emergir por todo o ambiente circundante. Com a capacidade de processamento de informação integrada, os produtos vão possuir habilidades de inteligência. Eles poderão também adquirir identidades eletrônicas que podem ser pesquisadas remotamente ou serem equipados com sensores para detectar mudanças físicas no seu entorno. Objetos estáticos e mudos tornar-se-ão seres dinâmicos e comunicantes, incrustando inteligência nos ambientes. No momento em que os objetos se tornarem inteligentes, $\mathrm{o}$ mundo das coisas e o mundo humano estarão se comunicando sob condições inéditas.

\section{Os projetos de mídias locativas devem ser avaliados à luz de contextos mais vastos da vida cotidiana, dos espaços públicos urbanos e, sobretudo, dos sistemas de controle e vigilância de que essas mídias fazem uso.}

Embora pareça que ainda não saímos da ficção científica de Sterling, o documento preconiza que tecnologias como RFID e computadores inteligentes prometem um mundo de dispositivos interconectados em rede que fornecerão conteúdo relevante e informação para qualquer lugar em que o usuário esteja. Qualquer coisa, da escova de dentes ao pneu do carro, entrará em faixas comunicacionais, anunciando o alvorecer de uma era em que a internet de hoje, de dados e de pessoas, conviverá com a internet das coisas. Essa será uma sociedade de redes ubíquas cujos dispositivos serão onipresentes. Germens dessa sociedade já se fazem sentir nas aplicações da terceira geração de telefones móveis que vem trazendo serviços de internet para o bolso dos usuários. O que dizer, entretanto, se muito mais do que isso fosse conectado às redes: um carro, uma frigideira, uma xícara de 
chá? À conexão de pessoas em qualquer tempo e em qualquer lugar, somar-se-á a conexão de objetos inanimados às redes de comunicação. $\mathrm{O}$ uso de tags eletrônicas (por exemplo, RFID) e sensores servirão para estender o potencial comunicacional e de monitoramento da rede das redes, assim como a introdução de poder computacional em coisas cotidianas, como lâminas, sapatos e sacolas avisando, por exemplo, que a chave da casa foi esquecida. Avanços na nanotecnologia (manipulação da matéria em nível molecular) irão acelerar esses desenvolvimentos. Estes são os prenúncios do documento. Embora soe ficcional, o mundo que nele se apresenta já começa a se insinuar nos projetos de mídias locativas.

Para McCullough (McCullough, 2006), fenômenos como habilidade espacial, escala e padrão físico persistente cavam as bases para uma virada tanto da mobilidade universal para uma aproximação mais socialmente centrada na computação situada, quanto das mídias meramente posicionais para o componente semântico dos modelos locativos. A computação pervasiva traz mobilidade, precisão, personalização e enraizamento na anotação urbana. Desse modo, as mídias locativas aumentam o acesso aos sistemas de informação geográfica, adicionam flexibilidade na sua filtragem e os apresentam de acordo com a atividade, desafiando-nos a fazer anotações em lugares de maneira não invasiva.

Quando bits imateriais de informação são conectados a localizações físicas no espaço público urbano, lugares e objetos cotidianos entram nas redes de computação inteligente, fazendo emergir novas práticas tecno-sociais com "o potencial de gerar espaços híbridos e formas de participação pública que reconectam as dimensões materiais do espaço público urbano com as affordances $^{9}$ participativas da esfera pública das redes" (Shepard, 2007).

Colocar geotags nos objetos, de modo que esses objetos nos contem suas histórias, leva-nos a conhecer sua genealogia, seu enraizamento na matriz de produção. Estamos entrando, portanto, em um mundo em que, por estarem ligados a chips inteligentes, os objetos vão se tornar sencientes, quer dizer, conscientes das impressões dos sentidos, o que nos trará a possibilidade de um engajamento mais ativo entre o corpo, a cidade, os lugares e as coisas.

Um exemplo bem simples de mídia locativa, que se comporta como internet móvel de lugares e coisas, nos é fornecido por Elanor Taylor (Taylor, 2004), no seu comentário sobre o Manifesto Headmap, de Ben Russell (Russell, 1999), considerado o ur-texto das mídias locativas. Basta a ligação de um dispositivo sensível a lugares (isto é, algo com funcionalidade GPS), com um computador portátil e uma conexão internet sem fio para que aconteça a situação descrita a seguir, pois esse trio fornece a plataforma necessária para trazer a tecnologia tradicional baseada em desk-top para o domínio do espaço.

Dois amigos têm acesso a essa tecnologia requerida. $\mathrm{O}$ amigo número um passa por uma árvore florida em plena primavera e conecta uma música a essa localização geográfica como uma mensagem para o amigo número dois. Sem saber que o amigo número um havia passado por aquele local antes dele, o amigo número dois, quando chega ao local em que está a árvore, é surpreendido pela árvore tocando a música para ele, pois a mensagem originalmente deixada pelo primeiro dispositivo é disparada pelo segundo dispositivo quando ele alcança aquele ponto geográfico marcado.

É claro que, sendo uma árvore, o lugar que canta adquire aí uma poética à altura da poética das flores na primavera. Entretanto, em pouco tempo, qualquer coisa, qualquer objeto material, uma mercadoria, um fetiche valorizado pelos humanos, irá se tornar um nó senciente em enredados processos de comunicação: o pó, o vidro, o telefone, todos terão alguma inteligência.

Evidentemente não se trata de proclamar aqui, sobre as tecnologias móveis, uma segunda versão do evangelho salvacionista do ciberespaço que dominou nos anos 1990. Os projetos de mídias locativas devem ser avaliados à luz de contextos mais vastos da vida cotidiana, dos espaços públicos urbanos e, sobretudo, dos sistemas de controle e vigilância de que essas mídias fazem uso. Bem a propósito, Lemos (ibid) nos lembra que não podem ser menosprezadas as questões não só comunicacionais ou urbanísticas, mas também políticas que emergem com as mídias locativas, questões "ligadas a novas formas de monitoramento, vigilância e controle do espaço urbano e da mobilidade social, já que tudo/ todos terão uma $\mathrm{tag}$, um indexador eletrônico, transformando os espaços das cidades em nuvens de dados". Todavia, como nos dizem Tuters e Varnelis (Tuters e Varnelis, 2006), o envolvimento nesse novo mundo de objetos, que começam a se comportar como seres animados, não deve ser dispensado, mesmo que os momentos utópicos e críticos, que soubermos fazer surgir, sejam apenas temporários e contingentes GFAmEcos

\section{NOTAS}

1. Para maiores descrições dessa divisão ver Santaella 2003 (introdução e cap. 4) e Santaella 2007 (caps 5 e 8$)$.

2. O sistema de posicionamento global (GPS) foi autorizado pelo Congresso dos Estados Unidos em 1973 e é operado pelo departamento de defesa dos Estados Unidos. Os instrumentos envolvidos nesse sistema são um anel de 24 satélites que circundam a Terra de modo tal que, pelo menos quatro deles, são visíveis de qualquer ponto no globo em qualquer momento. $\mathrm{O}$ sistema tem sido usado para a navegação de veículos, mas encontrou seu caminho também na internet móvel, quando o grupo de satélites é usado para localizar a posição de um usuário.

3. RFID é um método automático identificador de rádio 
freqüência que se baseia no arquivamento e recuperação de dados remotos utilizando os recursos das tags. Uma tag de RFID é uma etiqueta que pode ser incorporada a um produto, animal ou pessoa.

4. Uma tag, etiqueta, é um metadado, uma palavrachave ou termo associado a uma informação. Uma tag eletrônica é uma forma de vigilância não subreptícia em que um dispositivo eletrônico de GPS é colocado em um carro ou uma pessoa.

5. Definida pelo Consórcio Geoespacial Livre, a GML utiliza XML para exprimir características geográficas. Pode servir de linguagem de modelação para sistemas geográficos e como um formato aberto para troca de informação geográfica. A marcação de dados é um conceito recente e envolve a codificação simples de seqüências de dados em um arquivo de computador no formato texto-puro, ou seja, capaz de ser lido tanto por pessoas quanto por máquinas. Para esse fim, a linguagem mais utilizada atualmente é a XML e suas variantes.

\section{REFERÊNCIAS}

CASTELLS, Manuel. The rise of the network society. Malden, MA: Blackwell Publishers, 2000.

CERTEAU, Michel de. The practice of everyday life. Berkeley, CA: University of California Press, 1984.

DOCTOROV, Cory. Resenha. In BoingBoing-A directory of Wonderful Things. Disponível em <http:// www.boingboing.net/2005/10/26/bruce-sterlingsdesi.html>, 2005. Acesso em 15/01/2008.

DOURISH, Paul. Re-space-ing place: 'place' and 'space' ten years on. Disponível em <http://www.ics.uci.edu/ ijpd/publications/2006/cscw2006-space.pdf>, 2006. Acesso em 15/01/2008.

FERRAZ, Maria Cristina Franco. Tecnologias, memória e esquecimento: da modernidade à contemporaneidade. Revista Famecos 27, agosto 2005, 49-56.

GIBSON, James J. The ecological approach to visual perception. Hillsdalle, New Jersey: Lawrence Erlbaum, [1979] 1986.

HARRISON, Steve e DOURISH, Paul. Re-place-ing space: The roles of place and space in collaborative systems. Disponível em <http:/ / www.ics.uci.edu/ jpd/publications/place-paper.html>, 1996. Acesso em 15/ 01/2008.

LEMOS, André. Mídias locativas e territórios informacionais. In SANTAELLA, L; ARANTES, P. (eds.). Estéticas tecnológicas. Novos modos de sentir. São Paulo:
Educ, no prelo.

MCCULLOUGH, Malcolm. On urban markup: frames of reference in location models for participatory urbanism. Disponível em <http://leoalmanac.org/journal/ Vol_14/lea_v14_n03-04/mmccullough.asp>, 2006. Acesso em 10/01/2008.

RUSSELL, Ben. Headmap manifesto. Disponível em < http:/ /www.headmap.org/headmap.pdf>, 1999. Acesso em 22/06/2006.

SANTAELLA, Lucia. Culturas e artes do pós-humano. Da cultura das mídias à cibercultura. São Paulo: Paulus, 2003, 2a . ed. 2005.

Linguagens líquidas na era da mobilidade. São Paulo: Paulus, 2007.

.A estética política das mídias locativas. Revista Nómadas, Colômbia, no prelo.

SHEPARD, Mark. Locative media as critical urbanism. http:/ / transition.turbulence.org/blog/2007/ 09/04/locative-media-art/, 2007. Acesso em 10/01/2008.

STERLING, Bruce. Shaping Things. Cambridge, Mass.: Mit Press, 2005.

TAYLOR, Elanor. You know your place - Headmap manifesto and the specialized internet revolution. Social Issues Research Centre. Disponível em <http:/ / www.sirc.org/articles/know_your_place.shtml>, 2004. Acesso em 12/01/2008.

TUTERS, Marc e VARNELIS, Kazys. Beyond locative media. Disponível em <http://networkedpublics.org/ locative_media/beyond_locative_media>, 2006. Acesso em $11 / 12 / 2007$. 